\title{
Experimental and Numerical study of Mixed Convection in a Partially Opened Cavity with Tilted Baffle
}

\author{
Nabil Jamil Yasin ${ }^{\mathrm{a}}$, Kadhum Audaa Jehhef ${ }^{\mathrm{b}}$ and Asraa Mahdi Shakir ${ }^{\mathrm{c}}$ \\ a, Engineering Technical College-Baghdad, Middle Technical University, Baghdad, Iraq \\ b Department of Mechanics, Institute of Technology, Middle Technical University, Iraq \\ ,c Engineering Technical College-Baghdad, Middle Technical University, Baghdad, Iraq
}

\begin{abstract}
In this study the mixed convection heat transfer process in a square cross section cavity with a bottom groove heated from three side walls (left, right, and bottom) with vertically unheated baffle is investigated numerically and experimentally. In the numerical part the in-house CFD commercial code of ANSYS-FLUENT-V.16.0 based on finite volume method has been used to solve the $2 \mathrm{D}$ governing equations. The results are represented in terms of wall temperature profiles and Nusselt numbers of the heated wall. For the experimental work, a test rig were built to determine the effect of heater position, baffle height ratio $(\mathrm{h} / \mathrm{H})$, the baffle angle for the range of $300<\mathrm{Re}<1000$ and $1<\mathrm{Ri}<700$. The experimental results show a good enhancement about $(35 \%)$ in heat transfer can be obtained by using the baffle while the maximum values was by using right heater and with baffle angle $90^{\circ}$. The numerical flow visualization gives a good indication to temperature boundary layer and vortices location of flow. Good agreement was observed when comparing the experimental and numerical work and with other pervious work.
\end{abstract}

Keywords: Heat transfer, Mixed convection, Grooved cavity, Baffle.

\section{Introduction}

The mixed convection heat transfer problems in the various geometric shapes of the enclosure were presented in many studies such as rectangular enclosure, square enclosure, and arc-shape cavity. The early studies include a study of the mixed convection heat transfer in openended enclosures numerically for three different flow angles of attack presented by [1]. [2] studied the mixed convection in an open cavity with a heated wall bounded by a horizontally unheated plate. Their results showed that, the larger the distance between the vertical walls of the cavity, the lower the surface temperature and an increase of the surface temperature were observed at the same Reynolds number. [3] presented a study on the opposing mixed convection in a differentially heated partitioned enclosure. Their results showed that the heat transfer in case of opposing mixed convection is more than that of natural convection in centrally partitioned enclosure when the partition height exceeds $(1 / 3)$ of the enclosure height. [4] studied the effects of mixed convective flow over a three dimensional cubic cavity that lies at the bottom of a horizontal channel numerically. They considered an isothermal conditions for the vertical walls of the cavity and adiabatic conditions for all other walls for the range of Grashof number $\left(10^{3}-10^{6}\right)$ and two Reynolds numbers $\operatorname{Re}=100$ and 1000 . They found that at moderate Grashof number the flow becomes stable and exhibit a three-dimensional structure, while the mixed convection effects considered for both high Grashof and Reynolds numbers. [5] carried out a numerical study on the steady air flow free convection in a partially open square 2D cavity with internal heat source and the adiabatic condition given to the bottom and top walls, but the vertical walls were maintained at different constant temperatures by using a heat source located on the bottom wall of the cavity. Their results showed that the thermal and fluid dynamics of the fluid are highly influenced by the presence of the heat source, opening size and by the temperature difference between the vertical walls. [6] presented a numerical study to analyze the temperature distribution, flow field and heat transfer, in a channel with a cavity heated from its different sides. Three different cases were considered based on heater position in the cavity at the bottom side, left vertical side and right vertical side. [7] studied the thermal transport and fluid flow in a three-dimensional horizontal channel through an open-ended cavity by a comprehensive numerical investigation. The Reynolds numbers ranged between 100 and 1500, and Richardson numbers varied from 0.001 to 10. They found that, when the $(\mathrm{Ri})$ increases the part of the heated fluid moves close to the left side wall and the buoyancy forces become stronger. [8] presented a numerical work, flow structure and heat transfer characteristics in a channel with baffled grooved heated from the sides. The study considered the effects of the height and position baffle in the range of $0.1<\mathrm{Ri}<10$. They determined that an enhancement of heat transfer in presence of baffle. Finally, an unsteady numerical investigation on mixed convection in a two dimensional open ended cavity with different aspect ratios was presented by [9]. In his investigation, an uniform 
temperature is set to the left and the right sides of the cavity while the other surfaces are adiabatic. His simulation is performed for a wide range of Reynolds numbers $(\mathrm{Re}=100-1000)$ and Richardson numbers $(\mathrm{Ri}=$ $\left.0.132-6.5 \times 10^{2}\right)$, and various cavity aspect ratios (L/D = $0.5-4.0$ ) and $H / D=0.1$. It was noted that to achieve greater heat dissipation, it is better to have a heated surface aiding type configuration, which is in the same direction of air inlet into the channel. Also, the temperature profiles is, surely, that for which further decreases the L/D ratio, that is, more it tightens the cavity, the greater the temperature along the wall and inside the cavity.

The present work focused on the mixed convection in a cavity with and without baffles. The experimental work part includes a construction an experimental rig consists of a horizontal square cross sectional duct with a cavity having a baffle (considered to adiabatic) inserted at the top wall of the cavity while at the bottom of the cavity there is a cubic groove with three heated sides: left, right, and bottom wall. The numerical part includes building a computational model of the duct with the bottom groove and the baffle geometry which the same as the scaled geometries considered in the heat transfer analysis presented in the experimental work. The CFD computer software code, ANSYS-FLUENT-v.14.0 was employed in this work.

\section{Experimental Apparatus}

The experimental rig constructed for the present work is shown in Fig. (1) and the geometric dimensions of the duct is described in Fig.(2). The air flow was generated by using a centrifugal fan with impeller diameter $(100 \mathrm{~mm})$ and $(1300 \mathrm{rpm})$. The fan is capable to provide air with a range of speed between ( 0 to $6.6 \mathrm{~m} / \mathrm{sec})$. The entrance section of the employed duct was fabricated from a sheet stainless material having a thickness of $(2 \mathrm{~mm})$ to achieve the fully developed air flow. The duct was connected with the test section by a contraction part with a square screen grid to assess the smoothness of air flow. The test section was constructed of aluminum having a thickness of (5 $\mathrm{mm})$ square cross section with sides of length $(25 \mathrm{~cm})$. The cavity walls are perfectly insulated to ensure that no heat will follow across them. The baffle was made from aluminum plate with thickness of $(6 \mathrm{~mm})$ and placed vertically downward from the top wall perpendicular to the air stream. The baffle position was at the center of the groove. This baffle was equipped with a simple mechanism to facilitate changing the vertical position inside the cavity from ( $\mathrm{h}=0$ to $25 \mathrm{~cm}$ ). Moreover the mechanism allowed rotating of the baffle by different angles $\left(15^{\circ}, 45^{\circ}, 90^{\circ}\right.$ and $\left.135^{\circ}\right)$. Three uniform heaters with (700 Watt) were subjected to the vertical left, right and bottom walls of the bottom groove to provide a constant heat flux surface. The heater was powered with electricity by (Variac - HSN0101-4 Amp Max) to control the temperature required to heat up the left, right and bottom walls. It was supplied with voltage (0-220 Volt) giving a maximum current of (4 Amp). A Digital Clamp Meter (RE266) was used to measure the electricity powered to the heater (voltage and current) with an error deviation of $( \pm 0.5 \%)$ in voltage, and $( \pm 2 \%)$ in current There are two sets of experimental work, either cavity with baffle or without baffle. The baffle was mounted on the top wall of the cavity. The test section and U-cavity for duct were well insulated using the glass wool insulation to reduce the heat loss as much as possible.

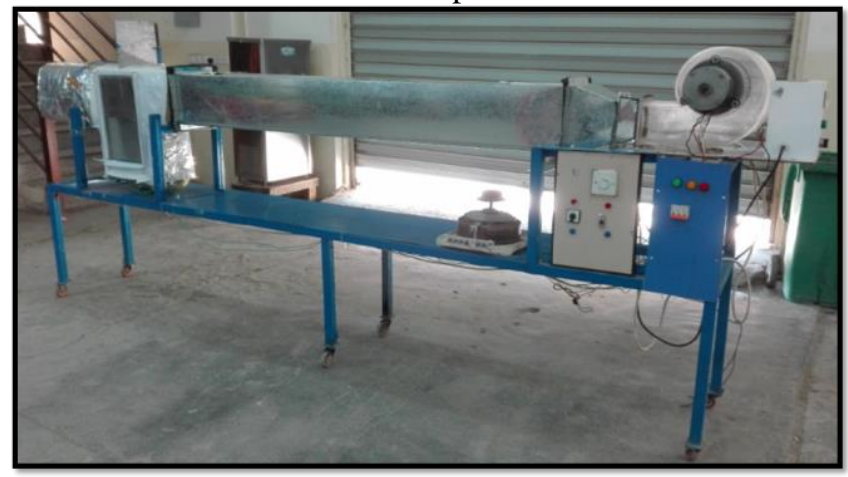

Fig.1 Experimental rig setup.

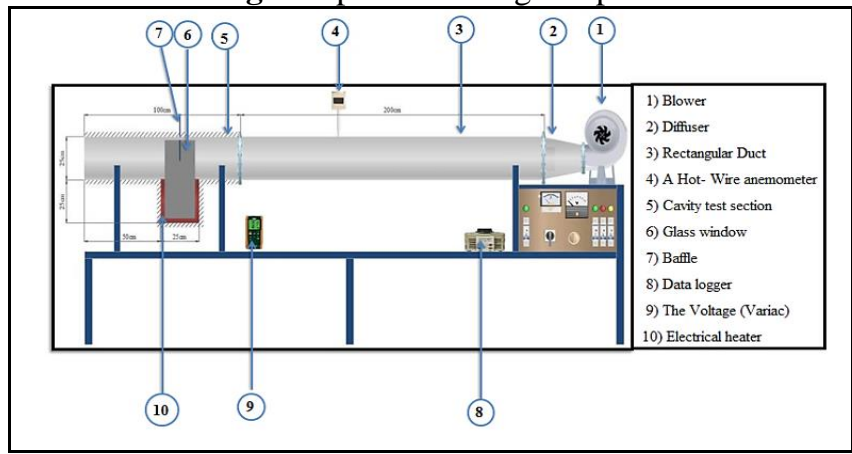

Fig.2 Schematic diagram of the experimental setup.

Nine thermocouples Type-K (Nickel 10\%, Chromium versus 5\% Aluminum, Silicon) were used to measure the temperature at different points in test section and the duct. The thermocouple junction and wires are fixed in its locations by a stainless steel rod of $(3 \mathrm{~mm})$ diameter and (100 mm) length. The thermocouples are distributed as follows: Two thermocouples $\left(\mathrm{T}_{1}\right.$ and $\left.\mathrm{T}_{2}\right)$, were used to measure the inlet and outlet temperature of the air. One thermocouples $\left(\mathrm{T}_{3}\right)$ was used to measure the surface temperature of the operating heater. Six thermocouples $\left(\mathrm{T}_{4}, \mathrm{~T}_{5}, \mathrm{~T}_{6}, \mathrm{~T}_{7}, \mathrm{~T}_{8}\right.$ and $\left.\mathrm{T}_{9}\right)$ were used to measure the temperature of the air, at the mid line of the bottom groove test section in top the cavity as shown Fig.(3) . A temperature recorder which has 12-channel model BTM4208SD equipped with a data logger uses SD memory card to save data which can be a loaded to an excel software. 


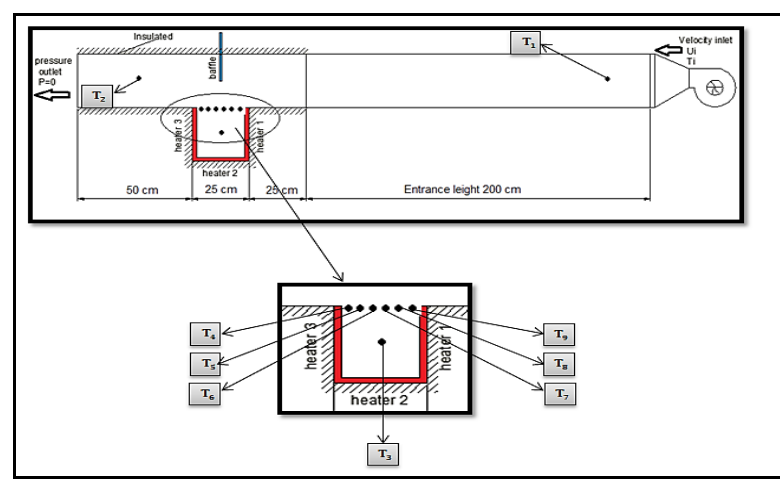

Fig. 3 Thermocouples positions in the test section.

\section{Data Reduction}

The heat flux delivered by the heaters can be known by:

$Q_{\text {heater }}=$ Power $=I V$

The heat absorbed by air in the test section was calculated as:

$Q_{\text {air }}=m_{a} c_{\rho a}\left(T_{\text {out }}-T_{\text {in }}\right)$

The heat transfer coefficient can be calculated by using: $\mathrm{Q}_{\text {conv }}=\mathrm{h}_{\text {ave }} \mathrm{A}_{\mathrm{s}}\left(\mathrm{T}_{\mathrm{w}}-T_{\text {ave }}\right)$

By using energy balance with assuming no heat losses the heat transfer of convection equals to the heat absorbed by air as follow:

$Q_{\text {conv }}=Q$ air

The heat transfer rate was calculated as:

$h_{\text {ave }}=Q_{\text {air }} / A_{s}\left(T_{w}-T_{\text {ave }}\right)$

The heated surface area can be calculated by using:

$\mathrm{A}_{\mathrm{s}}=\mathrm{L} * \mathrm{~W}$

The $\left(\mathrm{T}_{\mathrm{w}}\right)$ is the wall temperature, while $\left(\mathrm{T}_{\mathrm{ave}}\right)$ was obtained from the experiments by averaging six locations of measured temperatures along the mid line of the cavity.

$T_{\text {ave }}=\sum T_{\text {th }} / 6$

Where the mass flow rate of the air can be calculated by:

$m_{a}=\rho A V$

The density of air is at the inlet temperature of the test section and (A) is the cross section area of the inlet duct, while $(\mathrm{u})$ is the measured velocity in the cavity entrance. All the physical properties for the air were taken at mean film temperature $\left(\mathrm{T}_{f}\right)$.

$T_{f}=\left(T_{\text {out }}-T_{\text {in }}\right) / 2$

Other important parameters can be calculated as following Holman, (2012) [10]:

$N u=\mathrm{h} \cdot \mathrm{d}_{\mathrm{h}} / \mathrm{k}$

$\left.G r=\mathrm{g}^{\beta}\left(\mathrm{T}_{\mathrm{w}}-T_{\text {ave }}\right) \mathrm{H}^{3}\right) / \mathrm{v}^{2}$

$R e=\rho u d_{h} / \mu$

$R_{i}=\mathrm{Gr} / \mathrm{Re}^{2}$

\section{Numerical solution}

\subsection{Geometry Specification}

The geometry considered in this study is a twodimensional duct-cavity configuration, Horizontal square duct has $(\mathrm{H}=25 \mathrm{~cm})$ and exit length $(2 \mathrm{H})$, the square cavity depth equal to $(\mathrm{H})$. Air is introduced to the duct at a uniform velocity $\left(\mathrm{u}_{\mathrm{i}}\right)$, and at ambient temperature $\left(\mathrm{T}_{\mathrm{i}}\right)$. The air flow is assumed to be laminar, incompressible and the Prandtl number $\operatorname{Pr}=0.71$ with negligible viscous dissipation. The width and height of the heat source is $(\mathrm{H})$. The baffle is placed in on the upper duct wall. The governing equations for the system of the enclosed fluid are the expression for the conservation of mass, momentum, and energy transports at every point of the system within the limit of the basic assumptions and the use of appropriate boundary conditions.

\subsection{Mesh Generation}

In this work the grid was generated using a Mesh Elements type of Quad and Mesh Type of Map, and cluster the mesh elements nearest to surface of the heater surface in order to solve accurately the flow in the proximity of the later. A Global number of grid points of 131351 and Global number of elements: 129900 quadrilateral cells as shown in Fig. (4).

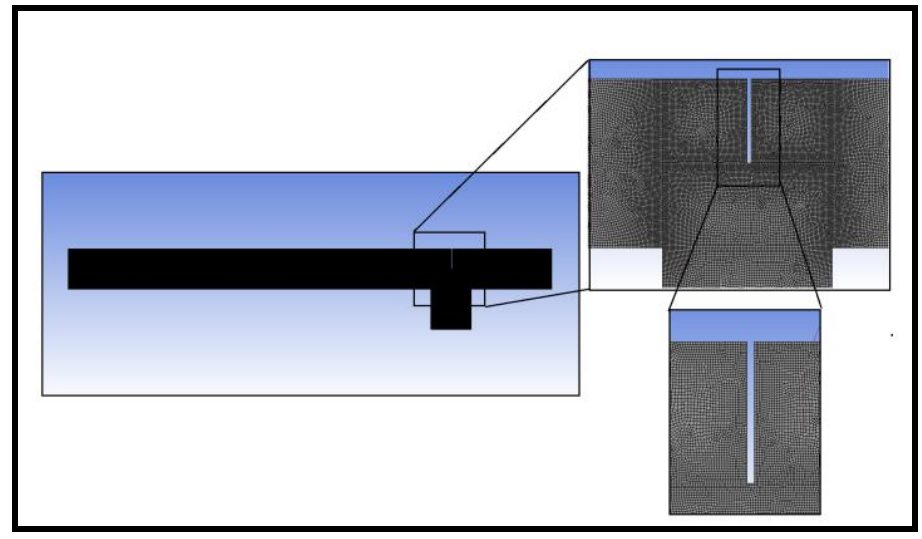

Fig.4 Variation of mesh density with total element number.

\section{Results and Discussion}

In order to understand the temperature field and heat transfer characteristics for the shielding effect of baffles on heat transfer by mixed convection in a square cavity by achieving a total (47) experiments were carried out presented and discussed in this section. To study the effects of baffle length selected run of $(5,12.5$ and $25 \mathrm{~cm})$ baffle height. It was measured from the top wall located at the center of the geometry. The fluid inside the cavity is dry air with $\operatorname{Pr}=0.7$ and Grashof number varied from $\left(1.2 \times 10^{7}\right.$ to $\left.8.3 \times 10^{7}\right)$.

\subsection{The Experimental Results \\ i) Temperature Distributions \\ a) Effect of Heater Positions}

Number of experiments were carried by mounting the heater at three different positions in the cavity (left, right and bottom) using a constant heat flux with a variable fan speed for the case without baffle insertion inside the cavity. The results for the air temperature distribution in the cavity are plotted against the dimensional axial distance with no variation of the applied heat fluxes as shown in Figs. (5) and (6) for $\mathrm{Re}=800$ and 1400 respectively. The results showed that the variation of the 
temperature along the top opening of groove of the cavity will be slightly change with time after $(50 \mathrm{~min})$ of operation and the differences between the values of temperature with time will be small. The comparison between the two figures showed that the level of the temperature values decreased as the Reynolds number increased from 800 to 1400

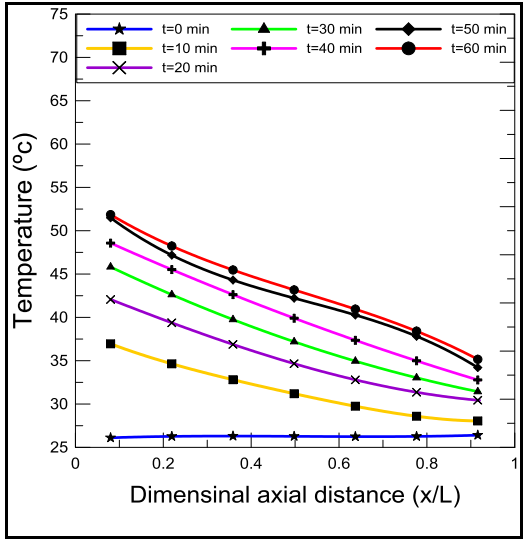

(a) Left heater

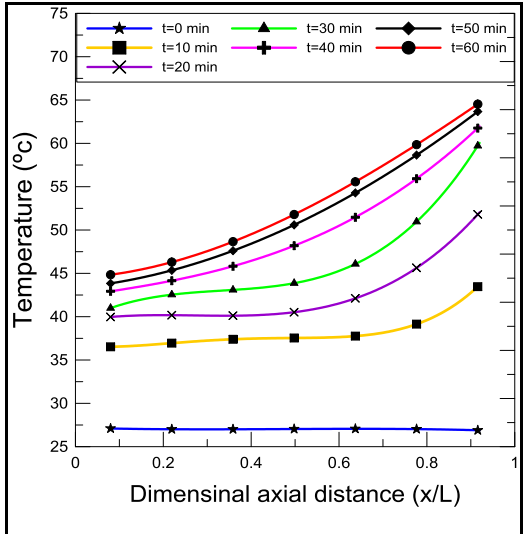

(b) Right heater

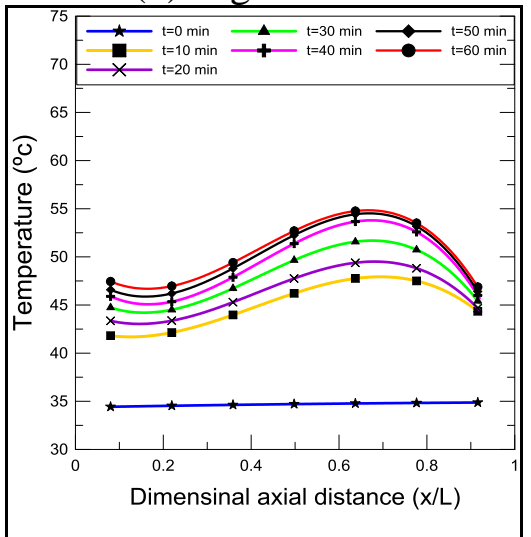

Fig.5 Temperature variation along the mid line of the cavity at $(q=500 \mathrm{~W}),(\mathrm{Re}=800)$.

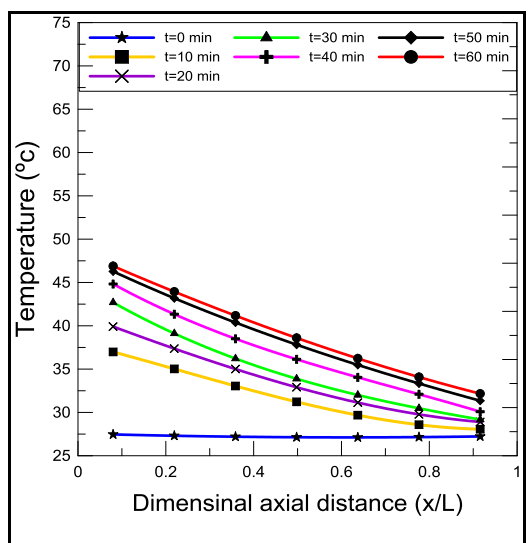

(a) Left heater

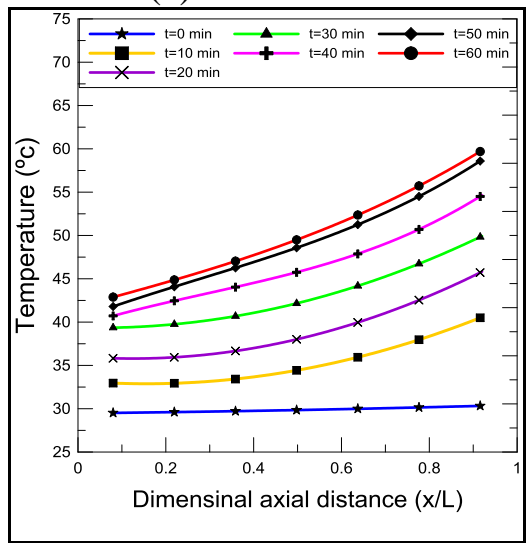

(b) Right heater.

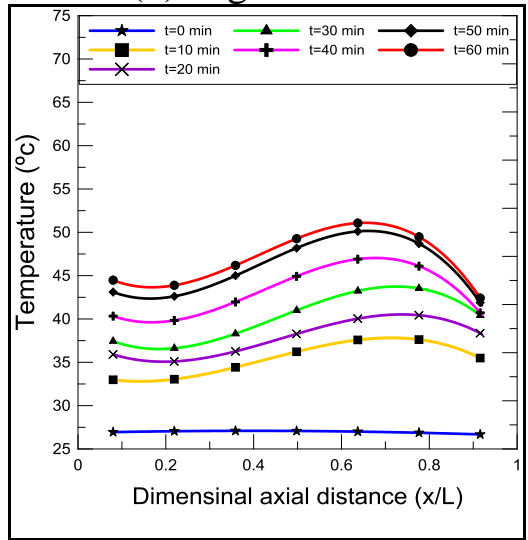

(c) Bottom heater.

Fig. 6 Temperature variation along the mid line of the cavity at $(\mathrm{q}=500 \mathrm{~W}),(\mathrm{Re}=1400)$

\section{b) Effect of the Reynolds Number}

Fig. (7) shows the variation of the air temperature values inside the cavity (without baffle) along the center line of the cavity at constant heat flux $(\mathrm{q}=300 \mathrm{~W})$ with different Reynolds Number and by changing the location of the heater. The figures shows that the air temperature inside the cavity is decreasing when the values of the $(\mathrm{Re})$ increasing due to increasing of air the velocity and increasing the cooling effect. However, Fig.(7a) showed that when the heater is mounted at the left side of the cavity in the direction of the (opposing flow), the value of temperature near that left heater is higher from the value far away from the heater. While it is clear the value of 
temperature near that right heater is higher from the value remote from heater as indicted by Fig.(7b). Where the flow be considered as assisting. For the assisting flow, the temperature gradient is larger close to the top corner, which is adjacent to the inlet cavity opening .Moreover when the heater is located at the bottom wall of the cavity, the difference between the temperature values at different position along the mid line of the cavity seems uniform as shown in Fig.(7c).

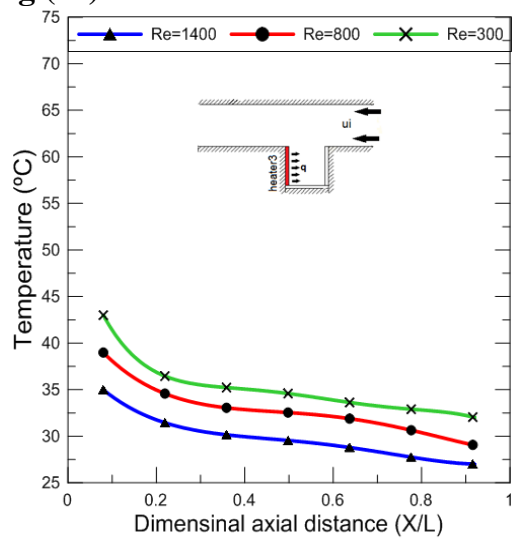

(a) Left heater.

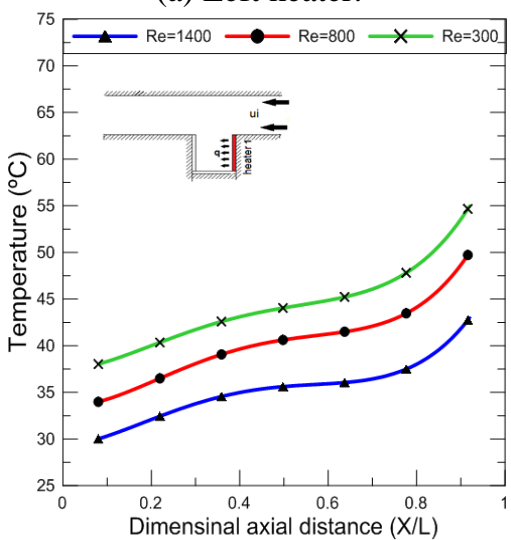

(b) Right heat

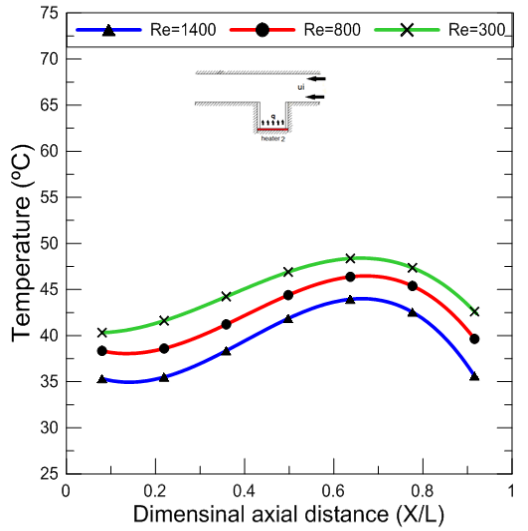

(c) Bottom heater

Fig.7 Temperature with dimensional axial distance at $\left(\mathrm{Gr}=10^{6}\right)$.

\section{c) Effect of Applied Heat Flux}

The effect of variation in heat flux on air temperature distribution is shown in Fig. (8) at constant Reynolds number $(\mathrm{Re}=800)$. The figure showed similar trend to the air temperatures for two Grashof numbers of $\left(\mathrm{Gr}=10^{6}\right.$ to
$10^{7}$ ). The air temperature is increasing when the values of the heat flux increase and reach to maximum values near of the left heater for opposing flow case while it reaches to the maximum values near the right heater.

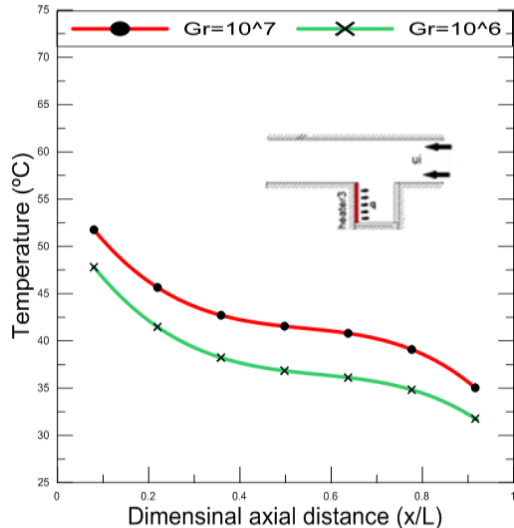

(a) Left heater

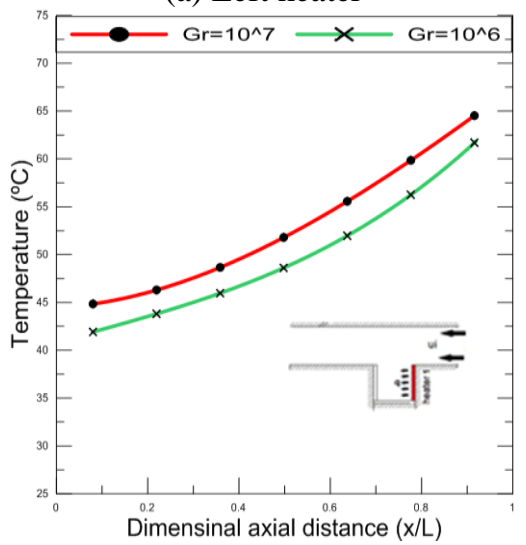

(b) Right heater

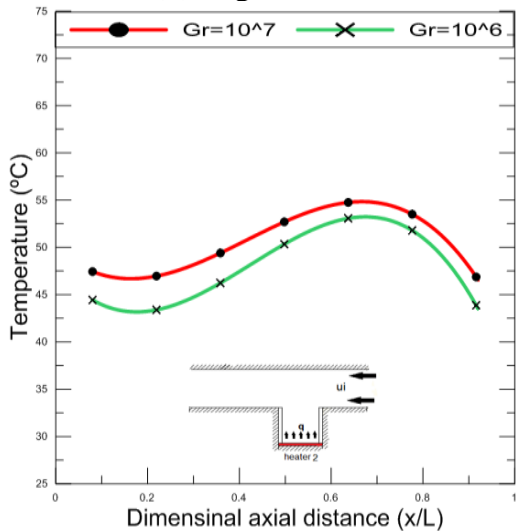

(c) Bottom heater.

Fig.8 Temperature variation with dimensional axial distance at $(\mathrm{Re}=800)$.

\section{d) Effect of the Baffle Height and Angle}

Fig. (9) represent the variation of the air temperature values inside the cavity by using different baffle height changing and the location of the heater. The results show that the air temperature values inside the cavity decrease with increasing the values of the baffle height ratio. Fig. (10) presented the variation of the air temperature values inside the cavity along the center line of the cavity with different angle of the baffle for the case bottom heater (heating from below) at height baffle $(\mathrm{h}=12.5 \mathrm{~cm})$ and 
$(\operatorname{Re}=800)$. The curves indicate that the values of temperature is higher at angle $\left(\theta=90^{\circ}\right)$ and seems lower value at the angle $\left(45^{\circ}\right.$ and $\left.135^{\circ}\right)$ due to decreasing the hot circulation inside the groove of the cavity at this angles.

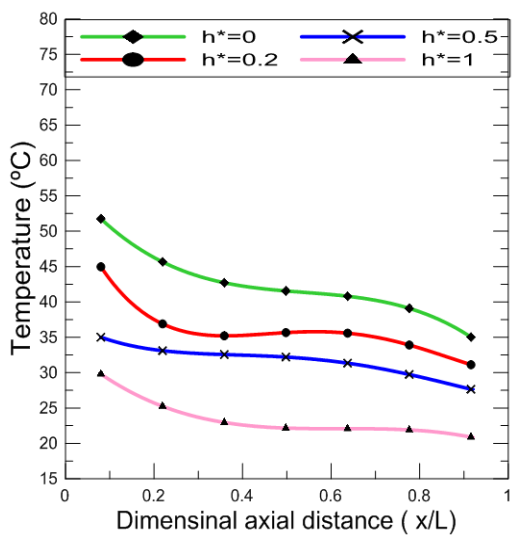

(a) $\mathrm{Re}=300$

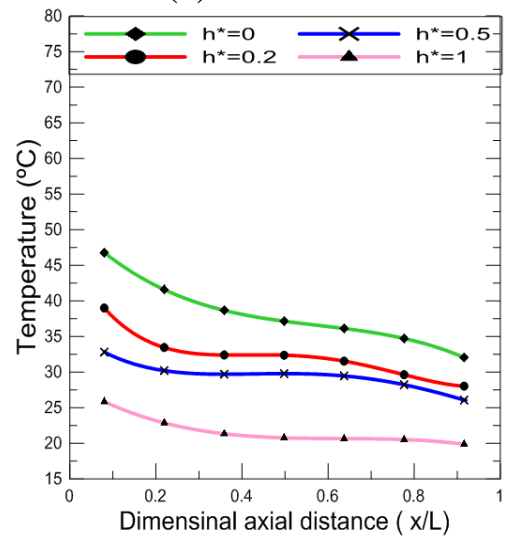

(b) $\mathrm{Re}=1400$

Fig. 9 Temperature with dimensional axial distance at $\left(\mathrm{Gr}=10^{7}\right)$ for the left heater.

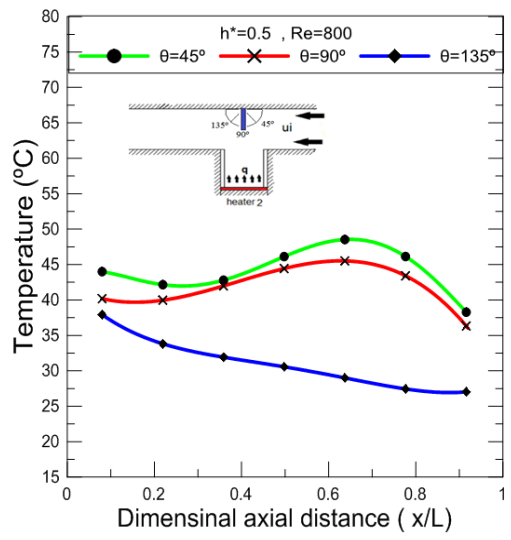

Fig.10 Temperature variation with dimensional axial distance at $(\mathrm{Re}=800, \mathrm{q}=500 \mathrm{~W})$ and $(\mathrm{h}=12.5 \mathrm{~cm})$.

\section{ii) Average Nusselt number}

The variation of the average Nusselt number with the Reynolds number for various heater position in case without baffle was presented Figs. (11) and (12). It was showed that the $\mathrm{Nu}$ increases with increasing the applied heat flux also with increasing the Reynolds number for the heater all positions. But the Nu values increase when using the right heater by $35 \%$ and $46 \%$ greater than the bottom heater and the left heater respectively at $(\mathrm{Re}=800)$ and $\left(\mathrm{Gr}=10^{6}\right.$ to $\left.10^{7}\right)$ due to the increasing of the heat convection in this position.

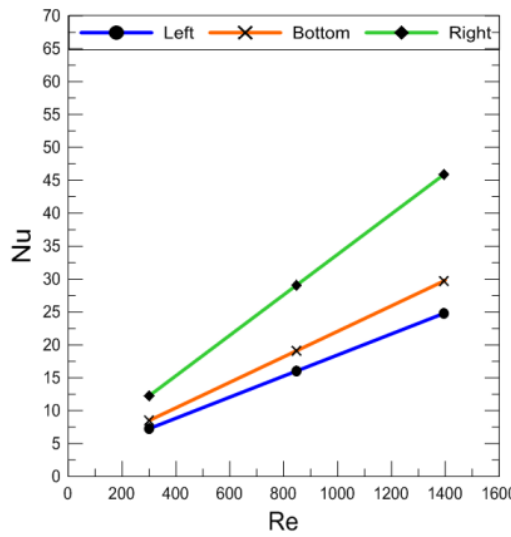

(a) $\mathrm{Gr}=10^{6}$

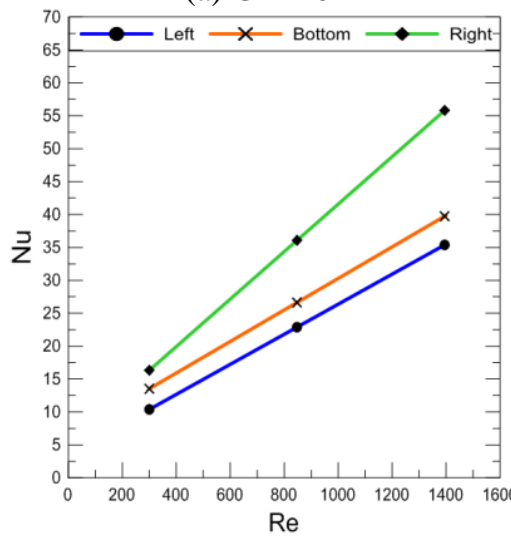

(b) $\mathrm{Gr}=10^{7}$

Fig.11 Variation of Nusselt number with Reynolds number for the cavity $\left(\mathrm{h}^{*}=0\right)$.

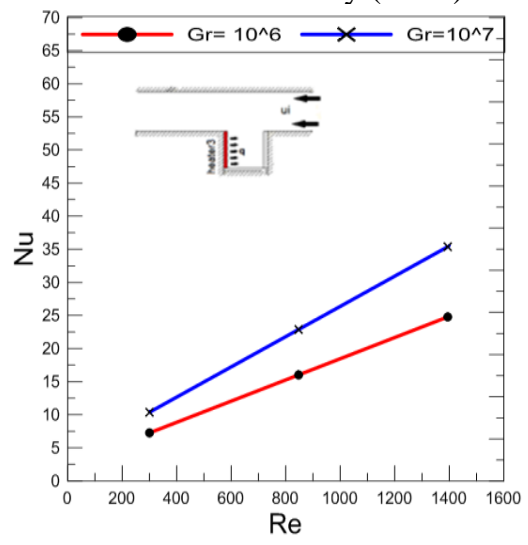

(a) Left heater 


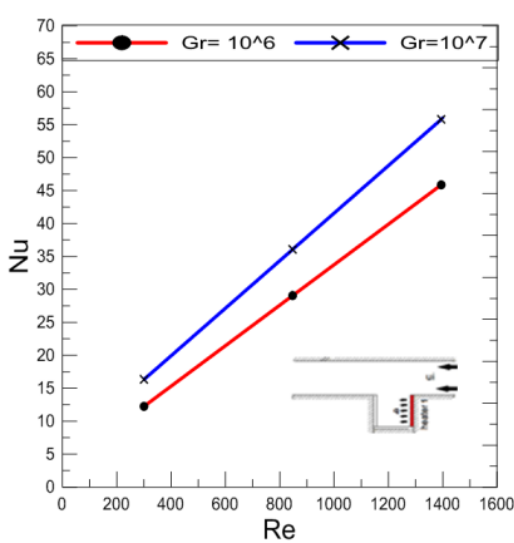

(b) Right heater

Fig.12 Variation of Nusselt number with Reynolds number for the cavity at $\left(h^{*}=0\right)$.

The Richardson number represents the ratio of the natural effect to the forced convection heat transfer effect which gives a good indication to the mixed convection. Fig. (13) shows the variation of the $(\mathrm{Nu})$ with $(\mathrm{Ri})$ for cavity region in the case of without baffle by using constant $\left(\mathrm{Gr}=10^{6}\right.$ to $\left.10^{7}\right)$. Nusselt number increases as the Richardson number decreasing as the natural convection effect was dominated at $(\mathrm{Ri}=300)$. The forced convection effect was dominated at $(\mathrm{Ri}=1$ to 10$)$ due to increasing the effect of Reynolds number. Moreover, the values of the $\mathrm{Nu}$ becomes at maximum values in the case of using the left heater.

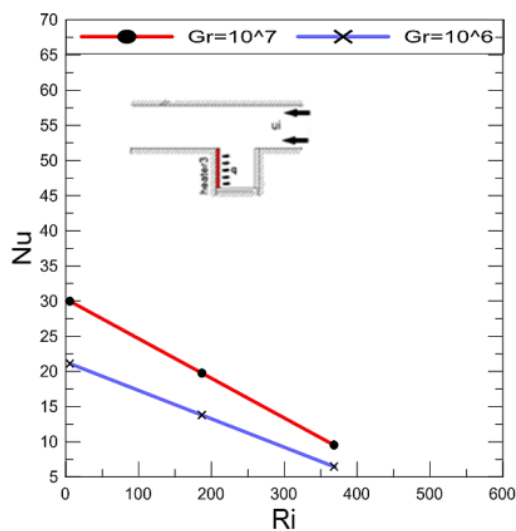

(a) Left heater.

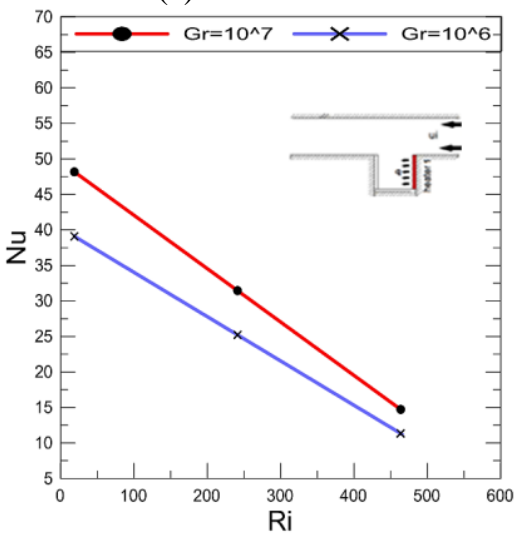

(b) Right heater.
Fig.13 Variation of Nusselt number with Richardson number for the cavity at $\left(h^{*}=0\right)$.

A comparison of variation of the average Nusselt number with Reynolds number in the case of using $\left(h^{*}=0.2\right.$ and 1.0) are presented in Fig.(14). It shows a good enhancement in heat transfer rate for a different position of heater. It is shown that the values Nusselt number of left heater is more than that of right and the bottom heater with using a baffle height ratio of $\left(h^{*}=0.2\right)$. As the baffle height ratio increases to $\left(h^{*}=1.0\right)$ it can be shown that the Nusselt number of bottom heater becomes be more than that of the left heater. The results shows that the Nusselt number increases with increasing the Reynolds number and with increasing the height baffle.

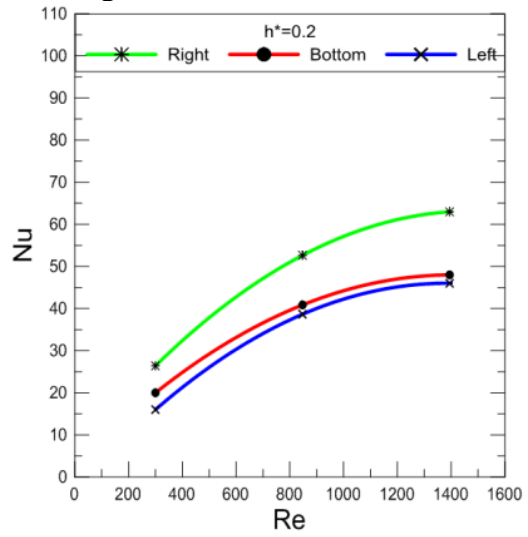

a) $h^{*}=0.2$

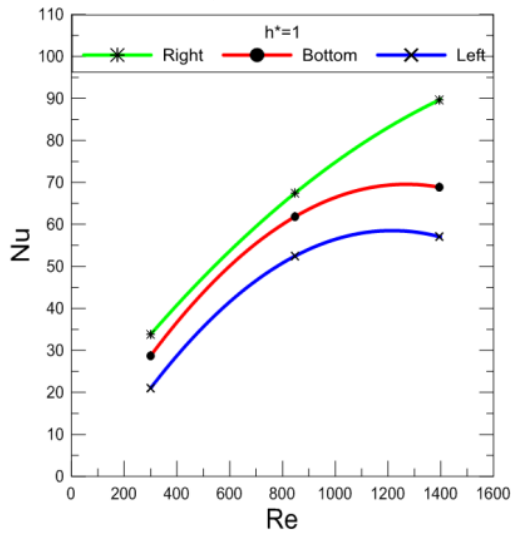

b) $\mathrm{h} *=1$

Fig.14 Variation of Nusselt number and Reynolds number with different height baffle at $\left(\mathrm{Gr}=10^{7}\right)$.

Fig. (15) shows the variation of Nusselt number with Richardson number at constant heat flux $\left(\mathrm{Gr}=10^{7}\right)$ in the case of using the baffle crossed the air flow above the heated groove. The results shows that the Nusselt number increases with decreasing the Richardson number for all conditions. 


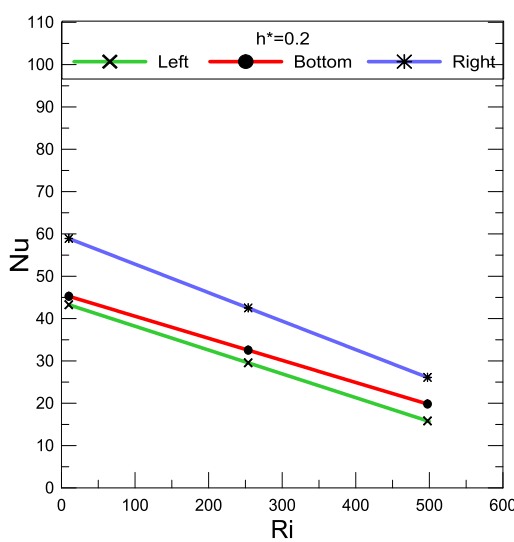

a) $h^{*}=0.2$

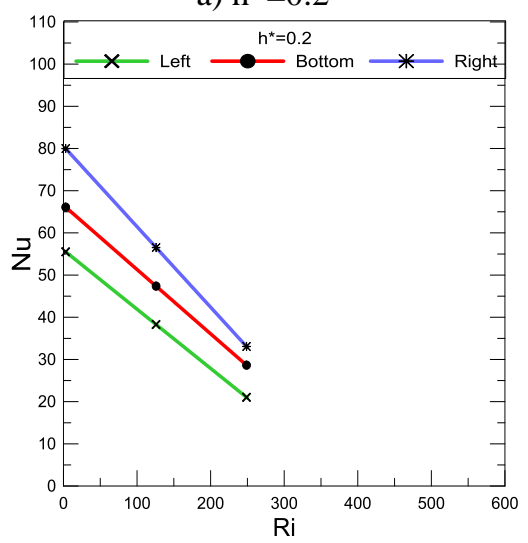

b) $h^{*}=1$

Fig.15 Variation of Nusselt number and Richardson number with different height baffle at $\left(\mathrm{Gr}=10^{7}\right)$.

\subsection{Numerical Results}

To validate and comparison of the present numerical work with the results given by Sharma, et al., (2015) the numerical work for streamlines and isotherms for flow from right condition at $\mathrm{Re}=200, \mathrm{Ri}=1$ are presented in Fig.(16). The results show a good agreement by the profile of the flow velocity and temperatures distribution.

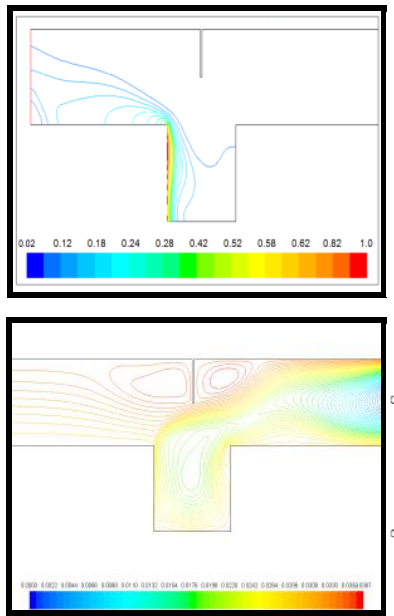

a) Present work
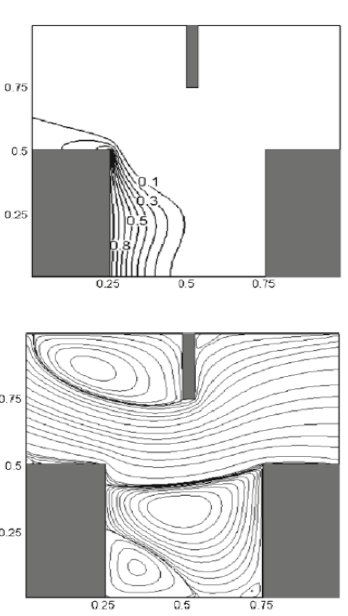

b) Sharma, et al., (2015)
Fig.16 Isotherms and streamlines for flow from left heater condition at $\mathrm{Re}=200, \mathrm{Ri}=1$.
The isotherm contours for three different locations of the heater at $\left(\operatorname{Re}=300, \mathrm{Gr}=10^{6}\right)$ were plotted in Fig.(17) to study the effect of heater position on the visualization of the temperature distribution in the cavity region and in the groove region. It was noticed that when using left heater Fig.(17a) the temperature contours stratified align the heater in the groove region and thermal boundary layer was very thinner without in any cell circulation inside the grove area. But when applied the heater power on the right heater Fig.(17b) temperature contours spreader inside the cavity region and thermal boundary layer becomes thicker than the first case, and the contours began to generate a large cell of circulation inside the grooved region. In case of bottom heater Fig.(17c) shows that the temperature contours are more stratified horizontally due to the conduction phenomenon of the air in case of the heated horizontal surfaces, thus there is no circulation cell filled the groove in this case.

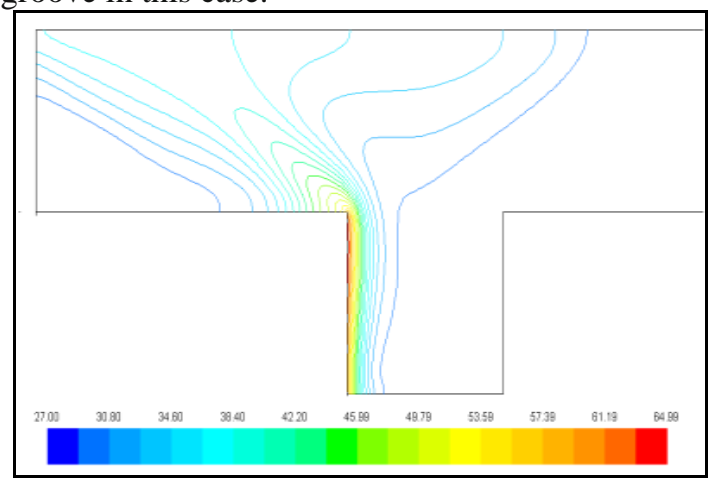

a) Left heater

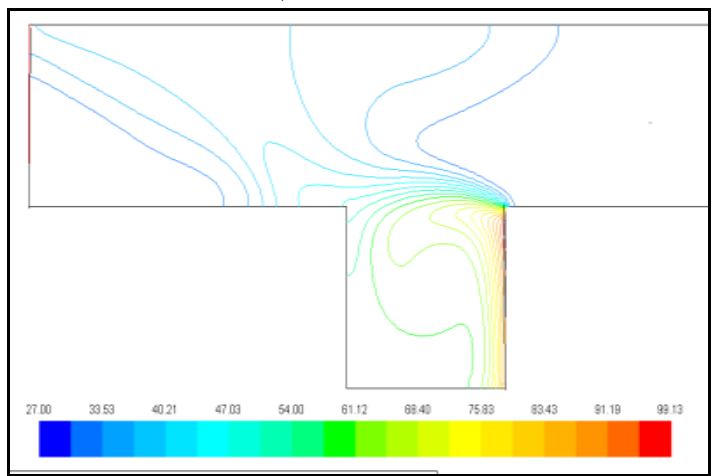

b) Right heater

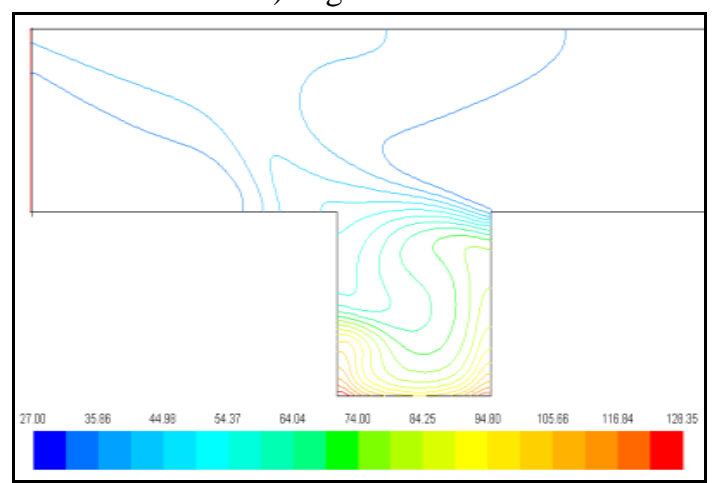

c) Bottom heater

Fig.17 Velocity lines for three heater positions of without baffle case $\left(h^{*}=0\right)$ at $\left(\operatorname{Re}=300, \mathrm{Gr}=10^{6}\right)$. 


\section{b) Effect of inlet Reynolds number}

Fig. 18 shows the contours of temperatures lines for without baffle case at $\mathrm{Re}=200$ and 1400 of the external flow from left condition. It is observed that when increasing the $\operatorname{Re}$ showed that the temperatures lines induced inward to the duct by the air flow.

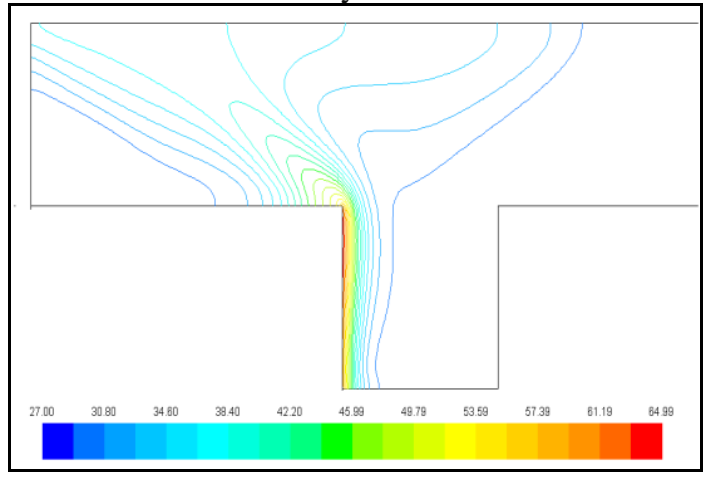

a) $\operatorname{Re}=300$

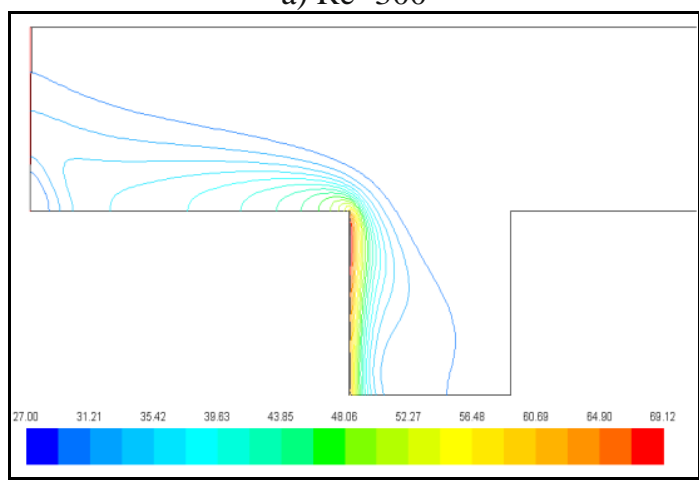

b) $\mathrm{Re}=1400$

Fig.18 Isotherms lines for Left heater positions of without baffle case $\left(\mathrm{h} *=0, \mathrm{Gr}=10^{6}\right)$.

\section{c) Effect of Applied Heat Flux}

Increasing the power of the heater and the heat flux from 300 to $500 \mathrm{~W}$ to get two Grashof numbers of $\left(\mathrm{Gr}=10^{6}\right.$ to $10^{7}$ ), leads to increase the temperatures along the right heater in the grooved cavity as shown in Fig. (19).

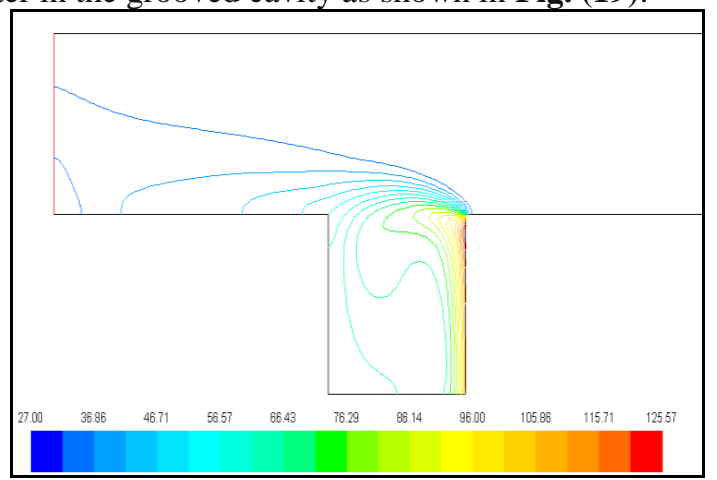

a) $\mathrm{Gr}=10^{6}$

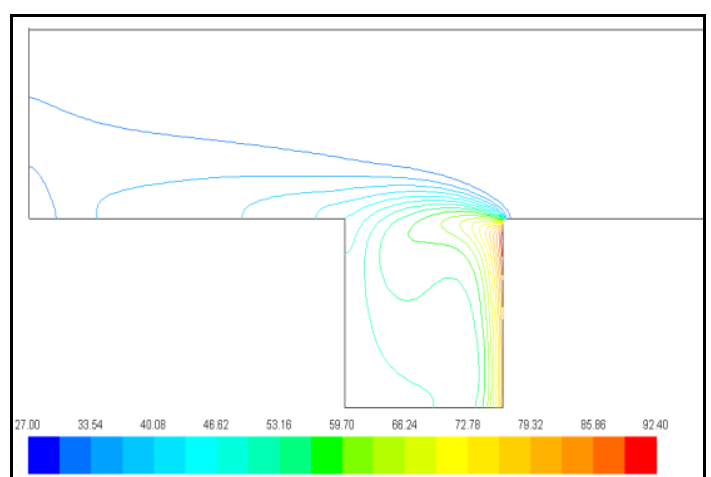

b) $\mathrm{Gr}=10^{7}$

Fig.19 Isotherms lines for right heater positions of without baffle case $\left(h^{*}=0, \operatorname{Re}=1400\right)$

\section{d) Effect of Baffle Height}

The isotherm contours lines three different baffle heights ratio $(\mathrm{h} / \mathrm{H})$ by $(0.2,0.5$ and 1$)$ at $\left(\theta=90^{\circ}\right)$ for left and right heater position at $\mathrm{Re}=300$ presented in Fig. (20). It shows that in the square cavity a distributed isotherm contours exist only for right at $\mathrm{Re}=300$. For left heater condition high valued contours are limited to regions near the hot wall while low valued contours dominate the other regions of the cavity. The presence of the baffle acts as an obstruction to the air flow, therefore, it notices that a more distributed contours at $\mathrm{Re}=300$. The isotherm contours for all baffle heights shows a low valued contours extending in the left end of the channel passage while the high valued contours mainly align to the regions near the heated wall.

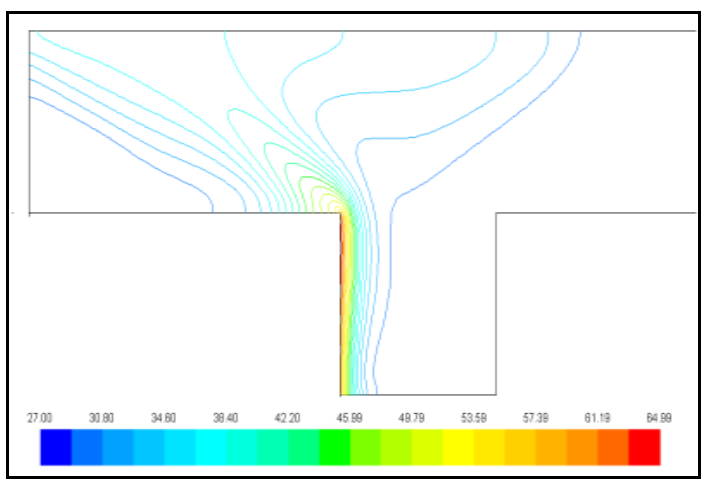

a) $\mathrm{h}^{*}=0.0$

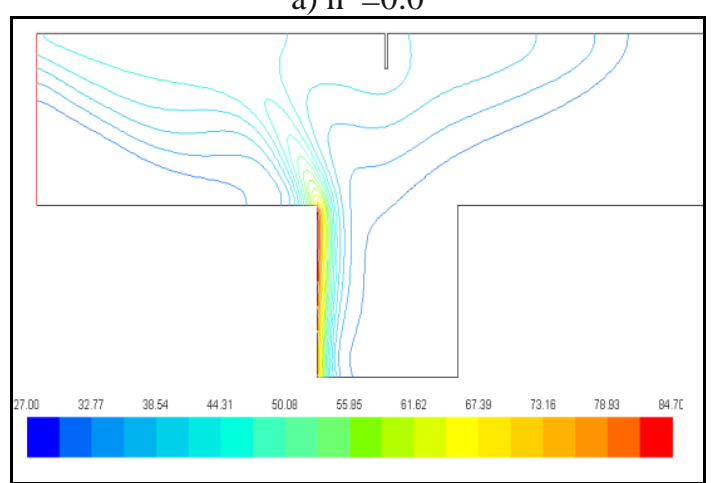

b) $\mathrm{h}^{*}=0.2$ 


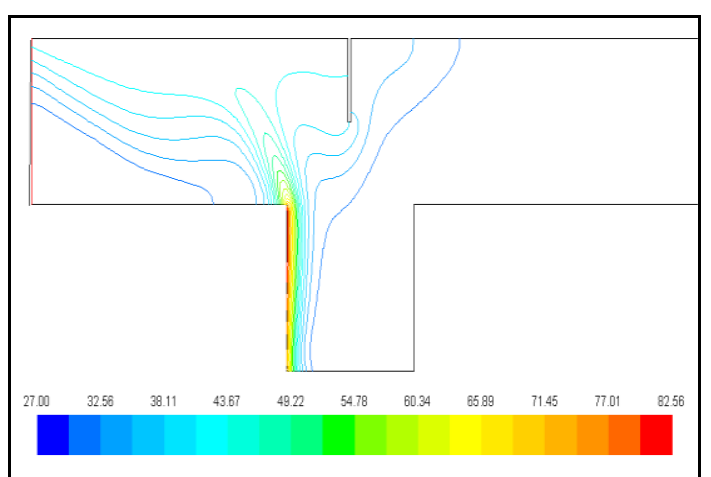

c) $h^{*}=0.5$

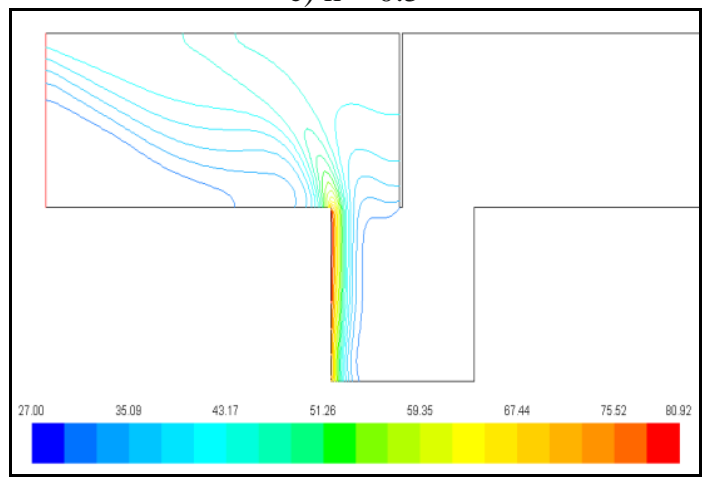

d) $h^{*}=1$

Fig.20 Isotherms lines generated by the left heater using three different baffle heights at $(\operatorname{Re}=300)$.

Figs. (21) shows the contours of velocity at $\mathrm{Re}=300$ for location of the left heater. It is observed that for different baffle height $\left(h^{*}\right)$. The results show that there is a circulating cell encompassing nearly the entire duct and extension to the cavity is formed, but when increasing the baffle height a circulating cell encompassing nearly the entire square cavity is formed. Thus, the height of the baffle plays an important role in the shape of the circulating cell formed in the square cavity and its bottom groove as well as the one behind the baffle. With increase in baffle height ratio to $(\mathrm{h}=1.0)$ as shown in Fig (21c), the flow is forced to enter and disturb the circulating cell formed in the square cavity.

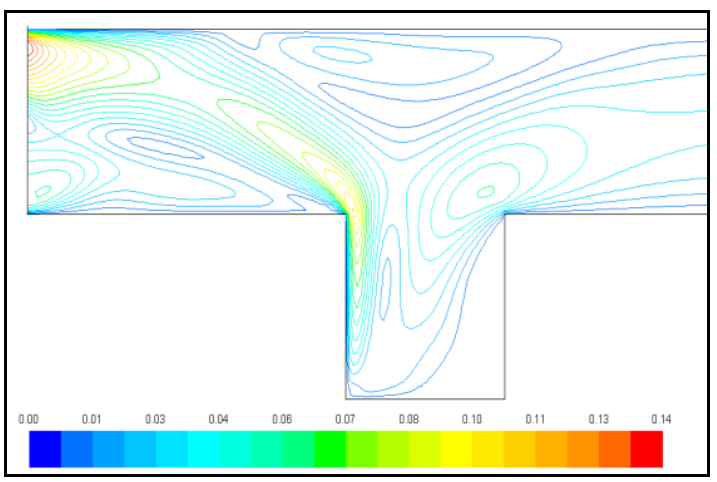

a) $h^{*}=0.0$

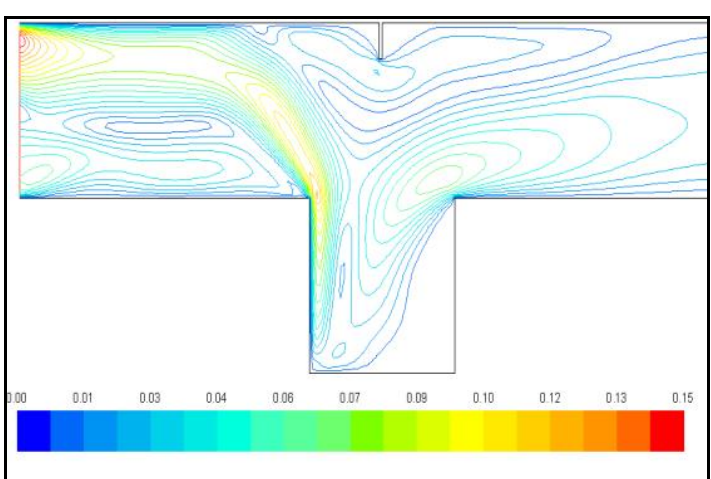

a) $h^{*}=0.2$

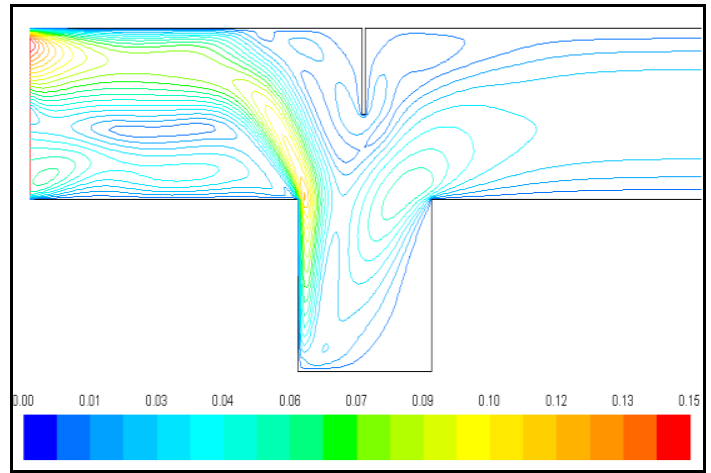

b) $\mathrm{h}^{*}=0.5$

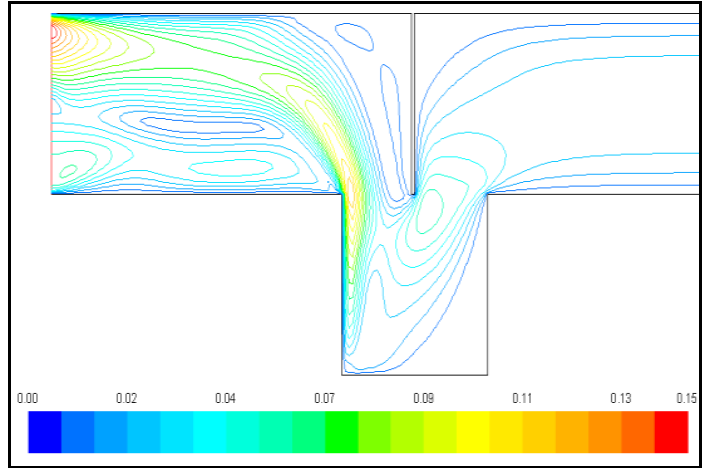

c) $\mathrm{h} *=1$

Fig.21 Velocity lines generated by the left heater using three different baffle heights at $(\operatorname{Re}=300)$.

\section{Comparison Experimental and Numerical Results}

Fig.22 showed the comparison between the present experimental and numerical study which shows a good agreement between them with a maximum deviation of $( \pm 17 \%)$ between the value of Nusselt number then case without the baffle. Also, a deviation of $( \pm 6.7 \%)$ for $\left(h^{*}=0.5\right)$ and $( \pm 6.1 \%)$ for $\left(h^{*}=1\right)$, this deviation due to the assumption and the boundary condition used here. 


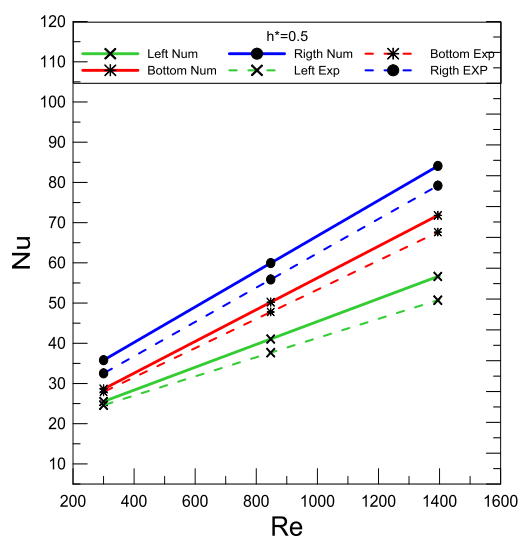

Fig.22 Average Nusselt number vs. Reynolds number for present experimental and numerical results $h^{*}=0.5$

\section{Conclusions}

An experimental and numerical investigation on mixed convection heat transfer in a partially open cavity with a square groove in the bottom wall was considered in this study. The bottom groove equipped by a three wall is (left, bottom and right) with variable applied heat flux. The baffle height ratio $\left(\mathrm{h}^{*}=\mathrm{h} / \mathrm{H}\right)$ was varied in its height by three values $(0.2,0.5$ and 1.0$)$. The experimental results presented in term of the top groove side temperature profiles and the heater wall Nusselt numbers according the flow parameter of $\mathrm{Re}=300$ to $1000, \mathrm{Ri}$ in the range 1 to 700. This results indicated that the temperature profiles affects sufficiently by the Re, Ri, and it increasing near the main stream the by increased the baffle height ratio $(\mathrm{h} / \mathrm{H})$ and with using a baffle orientation angle o $\left(\theta=90^{\circ}\right)$. The wall Nusselt numbers also Nusselt numbers increased when $(\mathrm{h} / \mathrm{H})$ increased in the investigated range of Richardson numbers, $10 \leq \mathrm{Ri} \leq 700$, for $\mathrm{Re}=300$ to 800 . The numerical flow visualization had pointed out that for $\operatorname{Re}=300$ and for the investigated Richardson numbers, there were two nearly distinct fluid motions: a parallel forced flow in the channel and a recirculation flow inside the cavity. These results were in a very good agreement with the previous work.

\section{Nomenclatures}

A Cavity cross sectional area, $\mathrm{m}^{2}$

$\mathrm{D}_{\mathrm{h}}$ Channel hydraulic diameter, $(4 \mathrm{~A} / \mathrm{P}), \mathrm{m}$

$\mathrm{h}_{\mathrm{av}}$ Average convective heat transfer coefficient, $\mathrm{W} / \mathrm{m}^{2} . \mathrm{K}$.

$\mathrm{h} *$ Baffle height ratio, $(\mathrm{h} / \mathrm{H})$

I Current, Amp

$c_{\rho}$ Specific heat, $\mathrm{J} / \mathrm{kg} \mathrm{K}$

g Gravity acceleration $\mathrm{m} / \mathrm{s}^{2}$

Gr Grashof-number

$\mathrm{H}$ Height of cavity, $\mathrm{m}$

h Height of baffle, $m$

$k$ Air thermal conductivity, W/m K

L Length of cavity, $\mathrm{m}$

$\mathrm{m}_{\mathrm{a}}$ Mass flow rate, $\mathrm{kg} / \mathrm{s}$

$\mathrm{Nu}_{\mathrm{av}}$ Average Nusselt number

$\mathrm{p}$ Pressure, $\mathrm{Pa}$

Pr Prandtl number

Q Heat transfer, W
Re Reynolds number

Ri Richardson number

$\mathrm{T}_{\text {th }}$ Temperature thermocouple $\mathrm{K}$

$\mathrm{u}$ Air velocity, $\mathrm{m} / \mathrm{s}$

V Voltage, volt

W Heated wall length, $\mathrm{m}$

$x / L$ Dimensional axial distance

\section{Greek letters}

$\beta$ Thermal expansion coefficient, $1 / \mathrm{K}$

$\theta$ Two walls orientation angles, degree

$\mu$ Molecular viscosity of the fluid, $\mathrm{Pa}$. sec

$v$ Kinematic viscosity of the fluid, $\mathrm{m}^{2} / \mathrm{sec}$

$\rho$ Fluid density, $\mathrm{kg} / \mathrm{m}^{3}$

\section{References}

[1] Khanafer, K., Kambiz Vafai b, Marilyn Light stone, (2002), Mixed convection heat transfer in twodimensional open-ended enclosures, International Journal of Heat and Mass Transfer 45, pp.51715190.

[2] Manca, O., and Sergio Nardini, Kambiz Vafai, (2006), Experimental Investigation of Mixed Convection in a Channel with an Open Cavity, Experimental Heat Transfer, 19:53-68, 2006.

[3] Mahapatra, S.K., Anjan Sarkar b, A. Sarkar, (2007), Numerical simulation of opposing mixed convection in differentially heated square enclosure with partition, International Journal of Thermal Sciences 46, pp.970-979.

[4] Stiriba, Y., F.X. Grau, J.A. Ferré, A. Vernet, (2010), A numerical study of three-dimensional laminar mixed convection past an open cavity, International Journal of Heat and Mass Transfer 53, pp.47974808.

[5] Fontana, E., Adriano da Silva, Viviana Cocco Mariani, (2011), Natural convection in a partially open square cavity with internal heat source: An analysis of the opening mass flow, International Journal of Heat and Mass Transfer 54, pp.13691386.

[6] Rahman, M.M., Hakan F. Öztop, N.A. Rahim, R. Saidur, K. Al-Salem, N. Amin, M.A.H. Mamun, A. Ahsan, (2012), Computational analysis of mixed convection in a channel with a cavity heated from different sides, International Communications in Heat and Mass Transfer 39, pp.78-84.

[7] Stiriba, Y., J.A. Ferré, F.X. Grau, (2013), Heat transfer and fluid flow characteristics of laminar flow past an open cavity with heating from below, International Communications in Heat and Mass Transfer 43, pp. 8-15.

[8] Sharma, A. K., Pallab S Mahapatra, Nirmal K Manna, and Koushik Ghoh, (2015) Mixed convection in a baffled grooved channel, Saadhana, Vol. 40, Part 3, May 2015, pp. 835-849, Indian Academy of Sciences. 
[9] Carozza, A. (2018), Numerical Study on Mixed Convection in Ventilated Cavities with Different Aspect Ratios, Fluids 2018, Vol. 10, Part 10, pp. 3242.

[10] Holman, J. P., (2012), experimental methods for engineers, eight edition, Department of Mechanical Engineering Southern Methodist University. 